\title{
2008-based national population projections for the United Kingdom and constituent countries
}

\section{Emma Wright}

Office for National Statistics

\section{Abstract}

The 2008-based national population projections, produced by the Office for National Statistics in consultation with the devolved administrations, show the population of the UK rising from 61.4 million in 2008 to 65.6 million in 2018 and 71.6 million by 2033. In the longer-term, the projections suggest that the population will continue rising beyond 2033 for the full length of the projection period. The population will become older with the median age expected to rise from 39.3 years in 2008 to $\mathbf{4 2 . 2}$ years by 2033. Despite the forthcoming changes to state pension age, the number of people of working age for every person of state pensionable age will reduce from 3.23 in 2008 to 2.78 by 2033. 


\section{Contents}

Abstract 91

Introduction. 94

Projection period 94

Base population 94

Underlying assumptions 95

Fertility 96

Mortality .98

Migration 100

Results of the 2006-based national population projections 101

Comparison with 2006-based projections 110

Sensitivity 111

Key findings 113

References 113

\section{List of figures}

Figure 1abc Assumptions for the 2008-based national population projections

Figure 2 Actual and projected population of the United Kingdom and constituent countries, 1971-2058

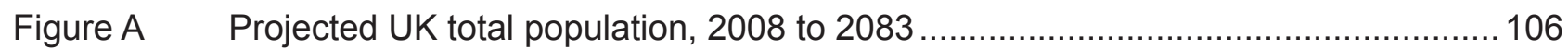

Figure $3 \quad$ Actual and projected births and deaths, United Kingdom, 1971-2058................ 107

Figure $4 \quad$ Actual and projected age distribution, United Kingdom, 1981-2058_.................. 108

Figure 5 Actual and projected old age support ratio, United Kingdom, 1981-2058 109

Figure 6 Population of the United Kingdom according to principal and variant 2008-based projections, 1981-2083

Figure 7 Proportion of the population aged 65 and over according to principal and variant 2008-based projections, United Kingdom, 1981-2083. 


\section{List of tables}

Table 1 Population change 2006-2008: actual change compared with 2006-based

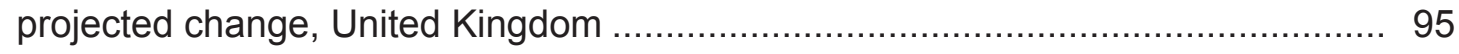

Table $2 \quad$ Summary of assumptions for individual countries ........................................ 97

Table A Period and cohort expectation of life, United Kingdom...................................... 100

Table 3 Components of change: summary (annual averages), 2008-2033...................... 102

Table A Projected population change, United Kingdom, 2008-33 ................................. 104

Table B Projected population growth by component, United Kingdom, 2008-33............... 104

Table A Projected population growth by component, United Kingdom ............................... 105

Table $4 \quad$ Projected population by age, United Kingdom, 2008-2033 .............................. 108

Table 5 Change in projected population at 2033 compared with the 2006-based projections 


\section{Introduction}

National population projections are produced for the UK and its constituent countries every two years. The latest set of projections is 2008-based; the principal projection and the key variant projections were published simultaneously on 21 October 2009, with additional variants published on 18 November 2009. Full results from the 2008-based principal and variant projections are available on the ONS website, ${ }^{1}$ while results for previous projections are available on the Government Actuary's Department (GAD) website. ${ }^{2}$

The 2008-based projections were produced by the Office for National Statistics (ONS) on behalf of the National Statistician and the Registrars General of Scotland and Northern Ireland. The underlying assumptions were agreed in liaison with the devolved administrations, following consultation with key users of the projections in each country and advice from an expert academic advisory panel. ${ }^{3}$

The projections use an internationally accepted standard cohort component methodology involving ageing on the population, adding projected births, subtracting deaths and adding assumed numbers of net migrants. Normally, a new set of national projections is made every second year, based on a full-scale review of the underlying assumptions about fertility, mortality and migration. The availability of subnational projections is discussed in Box one.

This report provides an overview of the results of the 2008-based national population projections and the underlying assumptions. More detailed information about the projections assumptions and methodology is provided in the 2008-based National Population Projections Reference Volume.

\section{Box one Subnational projections}

Subnational population projections are the responsibility of the statistical offices of the individual countries. The General Register Office for Scotland (GROS) published mid-2008 based subnational projections for Scotland, consistent with the national projections described in this article, on 3 February 2010. ${ }^{5}$ ONS, the Welsh Assembly Government Statistical Directorate and the Northern Ireland Statistics and Research Agency (NISRA) plan to release 2008-based subnational projections for England, Wales and Northern Ireland respectively in May 2010.

\section{Projection period}

The main focus of these projections is on the 25 years to 2033 . However, the results of longerterm projections are included in the graphs in this article and discussed where appropriate. In the detailed results available on the ONS website, the projections are carried forward for 75 years (that is, to 2083) for all countries. However, the long-term figures should be treated with great caution as population projections become increasingly uncertain the further they are carried forward, and particularly so for smaller geographical areas.

\section{Base population}

The projections are based on the official estimate (published on 27 August 2009) of the resident population of the UK at mid-2008 of 61.4 million. $^{6}$ 


\section{Table 1 Population change 2006-2008: actual change compared with 2006-based projected change, United Kingdom}

Thousands

\begin{tabular}{|c|c|c|c|c|}
\hline & \multirow{2}{*}{$\begin{array}{l}\text { Mid-year } \\
\text { estimates }\end{array}$} & \multirow{2}{*}{$\begin{array}{l}\text { 2006-based } \\
\text { projections }\end{array}$} & \multicolumn{2}{|c|}{ Difference } \\
\hline & & & $\begin{array}{r}\text { Number } \\
\text { (thousands) }\end{array}$ & Percentage \\
\hline Population at mid-2006 & 60,587 & 60,587 & 0 & $0.00 \%$ \\
\hline \multicolumn{5}{|l|}{ Components of change (2006-2008) } \\
\hline Births & 1,548 & 1,535 & 13 & $0.82 \%$ \\
\hline Deaths & 1,141 & 1,146 & -5 & $-0.47 \%$ \\
\hline Natural change & 407 & 389 & 18 & - \\
\hline Net migration and other changes* & 388 & 435 & -47 & - \\
\hline Total change & 796 & 824 & -29 & - \\
\hline Population at mid-2008 & 61,383 & 61,412 & -29 & $-0.05 \%$ \\
\hline England & 51,446 & 51,488 & -41 & $-0.08 \%$ \\
\hline Wales & 2,993 & 2,993 & 0 & $0.00 \%$ \\
\hline Scotland & 5,169 & 5,157 & 11 & $0.22 \%$ \\
\hline Northern Ireland & 1,775 & 1,774 & 1 & $0.08 \%$ \\
\hline
\end{tabular}

* Net movements of Armed Forces and other smaller changes.

Note: Natural change, net migration and total change can be positive or negative and hence it is not possible to express change in percentage terms.

As Table 1 shows, the estimated population of the UK at mid-2008 was 29 thousand ( 0.05 per cent) lower than envisaged in the 2006-based projections. This is largely explained by a combination of three factors: an underprojection of births during 2006-08 (13,000), an overprojection of deaths $(5,000)$ and an overprojection of net migration and other changes $(47,000)$. There were differences at individual country level, with England having an estimated population at mid-2008 that was 41,000 (0.08 per cent ) lower than expected from the 2006-based projections. In contrast, the populations of Scotland and Northern Ireland at mid-2008 were underestimated in the 2006-based projections, with the greatest relative error being for Scotland where the actual mid-2008 population was 0.22 per cent $(11,000)$ higher than projected.

A package of improvements for mid-year population estimates ${ }^{7}$ has been identified, and these will be implemented in May 2010, when revised population estimates for England and Wales for mid2002 to mid-2008 will be published. The base population for the 2008-based national population projections includes an adjustment for the expected national level impact of the revisions. The base population for England is therefore 13,000 higher than the published mid-2008 population estimate, whilst the base population for Wales is 3,000 lower than the corresponding published estimate.

\section{Underlying assumptions}

The assumptions used in the 2008-based national population projections are shown, for the UK as a whole, in Figure 1, while those for the individual countries are summarised in Table 2. 


\section{Figure 1a, b, c Assumptions for the 2008-based national population projections}

(a) Total fertility rate (TFR) and average completed

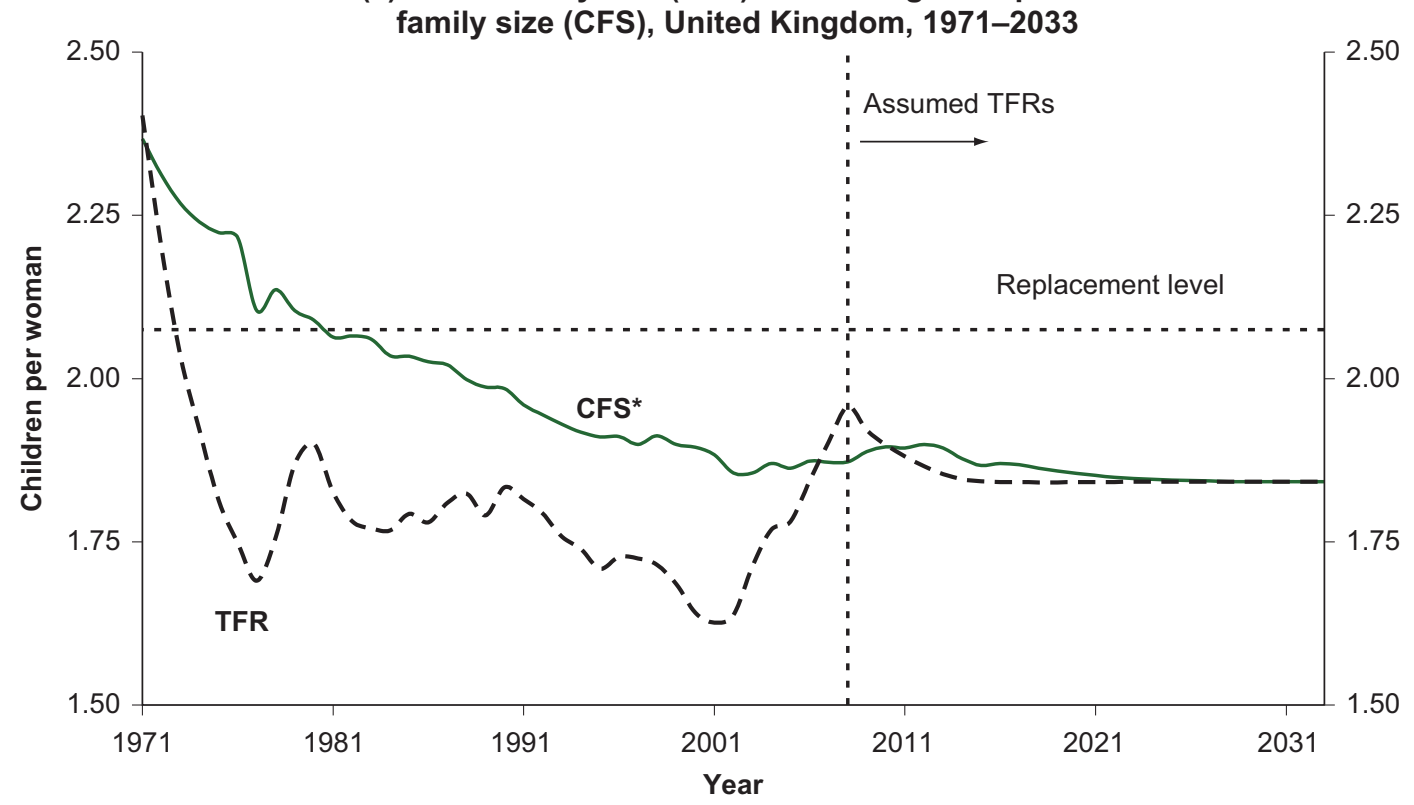

* Completed family size (CFS) relates to cohort born 30 years earlier - 30 years being the approximate mid-point of the childbearing ages. Projected CFS is given for cohorts who have not yet completed childbearing

Note: This figure is presented on a calendar year basis and for the TFR, shows a clear peak in actual fertility in 2008 , followed by a projected fall from 2009 onwards. When fertility rates are presented on a mid-year basis, this peak is smoothed out due to the high fertility in 2008 being split between 2007-08 and 2008-09.

(b) Period expectation of life at birth, United Kingdom, 1981-2083

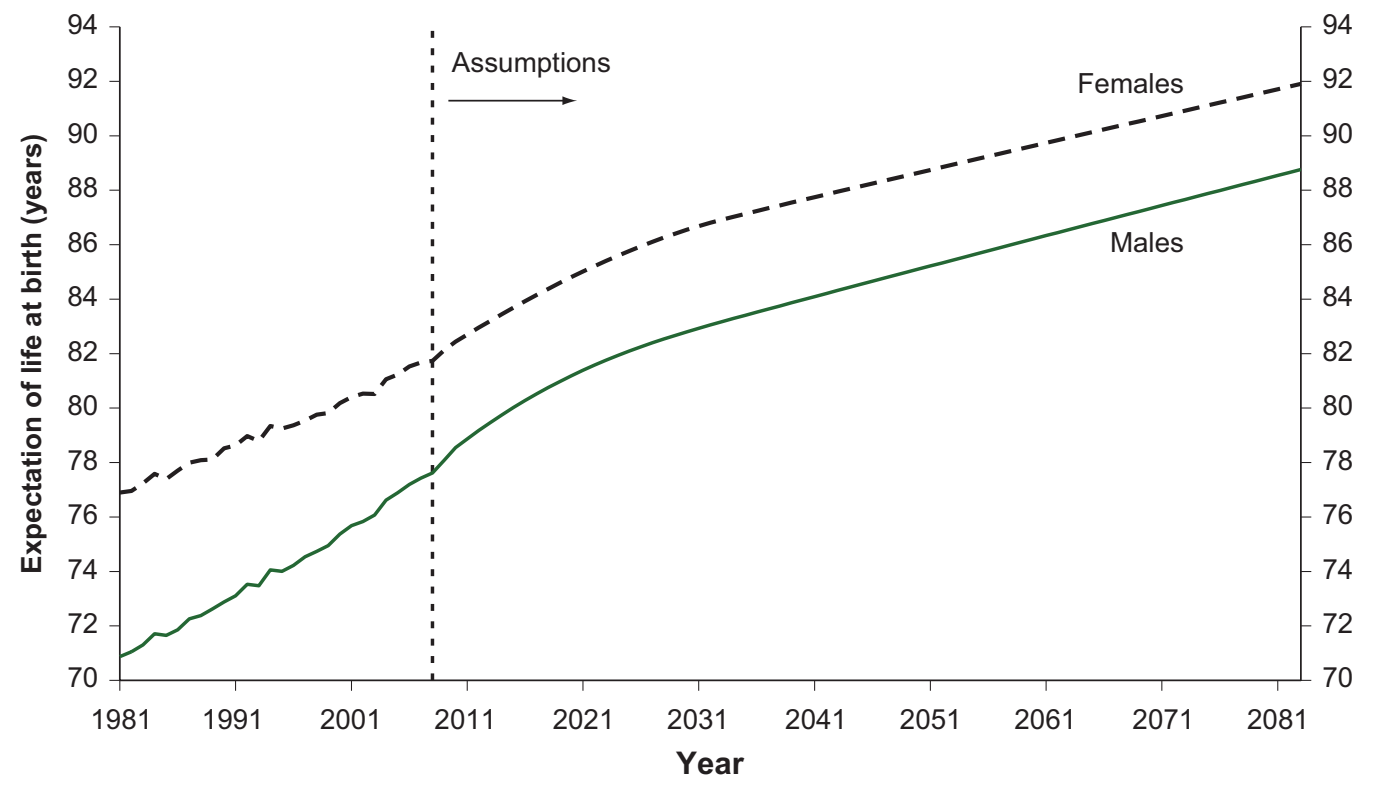

\section{Fertility}

Fertility assumptions are formulated in terms of the average number of children that women born in particular years will have. This cohort measure of fertility is more stable than the analogous calendar year or period measure (the total fertility rate, TFR), as it is affected only by changes in 
(c) Total net migration, United Kingdom, 1991-92 to 2020-21

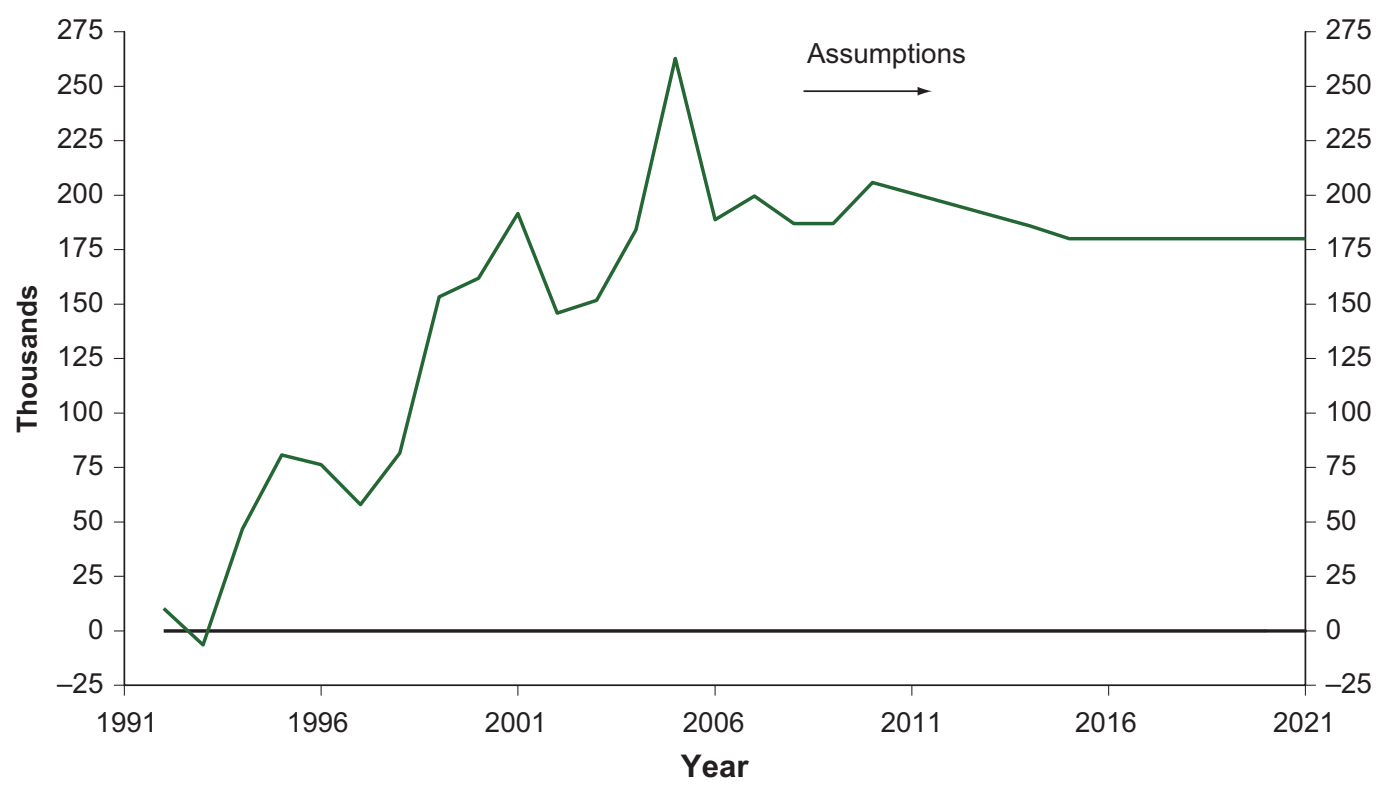

the total number of children women have and not by the timing of births within their lives. Period rates, in contrast, may rise or fall if births are brought forward or delayed for any reason. The assumed average completed family sizes and resultant TFRs are both shown in Figure 1a, while the TFRs for individual countries are summarised in Table 2.

The assumptions about completed family size are based on family building patterns to date and other relevant evidence. For the UK as a whole, completed family size has been falling steadily from an average of around 2.45 children for women born in 1935 to 1.94 children for those born

\section{Table $2 \quad$ Summary of assumptions for individual countries}

\begin{tabular}{|c|c|c|c|c|c|c|c|c|}
\hline & \multicolumn{4}{|c|}{ Total fertility rate } & \multicolumn{4}{|c|}{ Net annual migration (thousands) } \\
\hline & 2008-09 & 2011-12 & 2014-15 & $\begin{array}{r}\text { from } \\
2017-18\end{array}$ & 2008-09 & 2010-11 & 2012-13 & $\begin{array}{r}\text { from } \\
2014-15\end{array}$ \\
\hline England & 1.94 & 1.88 & 1.85 & 1.85 & 162.5 & 173.7 & 166.2 & 157.0 \\
\hline Wales & 1.93 & 1.88 & 1.85 & 1.85 & 5.5 & 9.1 & 10.8 & 10.5 \\
\hline Scotland & 1.78 & 1.72 & 1.70 & 1.70 & 16.0 & 16.2 & 12.9 & 12.0 \\
\hline Northern Ireland & 2.08 & 2.01 & 1.97 & 1.95 & 3.0 & 1.8 & 0.9 & 0.5 \\
\hline \multirow[t]{4}{*}{ United Kingdom } & 1.93 & 1.87 & 1.84 & 1.84 & 187.0 & 200.8 & 190.8 & 180.0 \\
\hline & \multicolumn{8}{|c|}{ Period expectation of life at birth (years) } \\
\hline & \multicolumn{4}{|c|}{ Males } & \multicolumn{4}{|c|}{ Females } \\
\hline & 2008-09 & 2012-13 & $2022-23$ & 2032-33 & 2008-09 & 2012-13 & $2022-23$ & 2032-33 \\
\hline England & 78.1 & 79.7 & 82.0 & 83.4 & 82.2 & 83.3 & 85.5 & 87.1 \\
\hline Wales & 77.2 & 78.9 & 81.3 & 82.7 & 81.5 & 82.8 & 85.0 & 86.6 \\
\hline Scotland & 75.5 & 76.9 & 79.2 & 80.7 & 80.2 & 81.4 & 83.6 & 85.2 \\
\hline Northern Ireland & 76.7 & 78.4 & 80.8 & 82.2 & 81.3 & 82.8 & 85.1 & 86.6 \\
\hline United Kingdom & 77.8 & 79.3 & 81.7 & 83.1 & 81.9 & 83.1 & 85.3 & 86.9 \\
\hline
\end{tabular}


in 1962, the most recent cohort to have reached the end of their childbearing years. The family sizes to be achieved by younger cohorts are highly conjectural, and there is some evidence that falls in cohort fertility could be slowing down. For this projection it has been assumed that average completed family size, for the UK as a whole, will remain below two children and eventually level off at 1.84 children for women born after 1995.

For England and for Wales, long-term average completed family size is assumed to be 1.85 children per woman. A higher level of 1.95 is assumed for Northern Ireland and a lower level of 1.70 is assumed for Scotland. These long-term assumptions are the same as the 2006-based assumptions for England, Wales and Northern Ireland, and slightly higher for Scotland. All the long-term assumptions remain well below 'replacement level' (see Box four).

Since 2002 TFRs have increased in all constituent countries of the UK. In 2008, the TFR (the average number of children who would be born per woman based on the fertility rates for that year) in each of the four countries was well above the long-term level assumed for the 2006-based projections. For the 2008-based projections, the TFR for the UK has been assumed to decrease from 2008-09 until reaching the long-term level around 2015. So, TFRs in the first few years of the projections are above those assumed for the long-term.

Over the past six years, fertility rates have been rising faster among women in their thirties and forties than for women in their twenties, so mean age at childbirth has continued to rise. The average age at motherhood for the UK as a whole is projected to increase from 28.0 years for women born in 1962 to a long-term level of 29.3 years for those born from 1990 onwards.

\section{Mortality}

The 2006-based projections assumed that mortality rates for most ages would converge to a common rate of improvement of one per cent a year at 2031 and continue to improve at that constant rate thereafter. However, for those born in the period 1923-1940 (who have experienced greater rates of improvement in the last 25 years) rates of improvement above one per cent were assumed from 2031 onwards.

The average annual rate of improvement over the whole of the twentieth century was around one per cent for both males and females, although the improvement rates vary by age. There continues to be considerable debate as to whether the impact of future lifestyle, medical and technological changes will have a greater or lesser impact in the future than they had over the last century. Therefore it was decided for the 2008-based projections to again assume an improvement rate of one per cent a year from 2033 onwards for most ages, with higher assumed rates of improvement for those born between 1923 and 1940 (rising from one per cent for those born before 1923 to a peak of 2.5 per cent for those born in 1931 and then declining back to one per cent for those born in 1941 and later).

As the projected age-specific annual rates of improvement prior to 2033 are generally higher than one per cent, this produces averaged annualised rates of mortality improvement of 1.3 per cent for males and 1.4 per cent for females over the next 76 years, which are about 0.1 per cent a year higher than those experienced over the past 76 years: 


\section{Actual and assumed overall average annual rates of mortality improvement, England and Wales, per cent}

\begin{tabular}{lrrrr}
\hline & \multicolumn{2}{c}{ Males } & \multicolumn{2}{c}{ Females } \\
\cline { 2 - 5 } & $\begin{array}{r}\text { Past } \\
\text { (actual) }\end{array}$ & $\begin{array}{r}\text { Future } \\
\text { (assumed) }\end{array}$ & $\begin{array}{r}\text { Past } \\
\text { (actual) }\end{array}$ & $\begin{array}{r}\text { Future } \\
\text { assumed) }\end{array}$ \\
\hline Last/next 26 years & 2.17 & 1.99 & 1.50 & 2.15 \\
Last/next 46 years & 1.59 & 1.56 & 1.36 & 1.65 \\
Last/next 76 years & 1.27 & 1.34 & 1.28 & 1.40 \\
\hline
\end{tabular}

Note: Historic estimates are based on comparison of the 2006-08 interim life tables with English Life Tables for 1930-32, 1960-62 and 1980-82.

For the UK as a whole, period life expectancy at birth, based on the mortality rates for the given year, is assumed to rise from 77.8 years in 2008-09 to 83.1 years in 2032-33 for males, and from 81.9 years to 86.9 years for females. These expectations of life in 2032-33 are around 0.2 years higher for males and 0.5 years higher for females than those assumed for the 2006-based projections.

Assumed expectations of life to 2032-33 for the individual countries are shown in Table 2. Current mortality levels differ between the individual countries. However, the same future improvements have been assumed for all countries of the UK except that some differences (generally slightly smaller improvements) in the period to 2033 have been assumed at some ages for males and females in Scotland. Therefore, the relative differences in life expectancy between the four countries are approximately maintained throughout the projection period.

The expectations of life shown in Table 2 are based on the mortality rates applying to a single year and are examples of period expectations of life. However, expectations of life can also be calculated on a cohort basis, allowing for known or projected changes in mortality rates in later years. Box two gives further information on the differences between period and cohort expectations of life.

\section{Box two Period and cohort expectations of life}

Expectations of life can be calculated in two ways: either period life expectancy or cohort life expectancy.

Period life expectancy is the average number of years a person would live if he or she experienced the age specific mortality rates for that time period throughout his or her life. It makes no allowance for any later actual or projected changes in mortality. In practice, death rates are likely to change in the future and so period life expectancy does not give the number of years someone could actually expect to live.

Cohort life expectancies are worked out using age-specific mortality rates which allow for known or projected changes in mortality in later years and are thus regarded as a more appropriate measure of how long a person of a given age would be expected to live, on average, than period life expectancy. 
For example, period life expectancy at birth in the year 2000 would be calculated using the mortality rate for age 0 in 2000, for age 1 in 2000, for age 2 in 2000, and so on. Cohort life expectancy at birth in 2000 would be calculated using the mortality rate for age 0 in 2000 , for age 1 in 2001, for age 2 in 2002, and so on.

In most official statistics, period life expectancies are given. Figures for past years provide a useful measure of mortality actually experienced over a given period and provide an objective means of comparing trends over time, between areas of a country and with other countries. However, they are often mistakenly interpreted by users as allowing for subsequent mortality changes. If mortality rates are projected to decrease in later years, then cohort life expectancy will be greater than period life expectancy.

Period and cohort life expectancies at individual ages for 1981 to 2058 for the UK and its constituent countries using historic mortality rates and projected mortality rates from the 2008based national population projections are available from the ONS website. ${ }^{8}$ Expectations of life at birth and at age 65 for the UK for the years 2008 and 2058 are shown in the Table A below.

\section{Table A Period and cohort expectation of life, United Kingdom}

\begin{tabular}{|c|c|c|c|c|}
\hline & \multicolumn{2}{|c|}{2008} & \multicolumn{2}{|c|}{2058} \\
\hline & Period & Cohort & Period & Cohort \\
\hline \multicolumn{5}{|c|}{ Life expectancy at birth } \\
\hline Males & 77.6 & 88.6 & 86.0 & 94.8 \\
\hline Females & 81.7 & 92.2 & 89.4 & 97.8 \\
\hline \multicolumn{5}{|c|}{ Life expectancy at 65} \\
\hline Males & 17.5 & 21.0 & 24.3 & 26.0 \\
\hline Females & 20.1 & 23.6 & 26.6 & 28.4 \\
\hline
\end{tabular}

Note: The life expectancies in this table relate to calendar years, and therefore may be slightly different to the mid-year life expectancies shown in Table 2.

The table shows that male life expectancy at birth in 2008 was 77.6 years based on the mortality rates actually experienced in that year. However, allowing for the future improvements in mortality assumed in the 2008-based projections, a boy born in 2008 can actually expect to live for 88.6 years. For females, the corresponding period and cohort life expectancies at birth in 2008 are 81.7 years and 92.2 years respectively. For a person aged 65 in 2008, cohort life expectancy (that is, taking account of assumed future improvements in mortality above age 65) is 3.5 years higher than period life expectancy for both sexes.

The differences between period and cohort life expectancies in fifty years' time are somewhat smaller. This is because mortality at most older ages is currently improving by more than the one per cent a year assumed from 2033 onwards.

\section{Migration}

Table 2 also summarises the annual net migration assumptions for each country of the UK. These combine assumptions regarding international migration to each of the constituent countries of the UK with assumptions about cross-border migration between each country. The new long-term 
assumption for net migration to the UK is $+180,000$ each year, compared with $+190,000$ a year in the 2006-based projections. Although estimates of total long-term international migration for 2008 were not available when the long-term assumptions were decided, it was possible to include provisional IPS estimates of long-term migration for 2008 within the long-term assumption setting procedures.

For the first few years of the projection period, net migration is assumed to be above the long-term annual level of $+180,000$ because of an allowance for additional net migration from the accession countries which joined the European Union in May 2004 and January 2007. This allowance reduces from $+25,000$ for $2009-10$ to zero for 2014-15 onwards. This reduction in net migration from the accession countries is in line with the published latest estimates of long-term international migration. ${ }^{10}$

Compared to the assumptions for the 2006-based projections, the long-term assumed level of annual net migration to England is 14,500 lower, whilst the assumed levels of annual net migration to Wales and Scotland are 1,000 and 3,500 higher respectively. These changes reflect the most recent trends in both international migration to, and cross-border migration between, the four countries of the UK.

\section{Results of the 2006-based national population projections}

\section{Total population}

The results of the new projections are summarised for the constituent countries of the UK in

\section{Table 3 and Figure 2.}

The population of the UK is projected to increase from 61.4 million in 2008 to reach 71.6 million by 2033. This is equivalent to an average annual rate of growth of 0.7 per cent during this period. In the longer-term, the projections suggest the population will continue rising beyond 2033 although at a slower rate of growth.

The population of England is projected to increase by 18 per cent by 2033 , Northern Ireland by 14 per cent and Wales by 12 per cent. The projected increase for Scotland, where fertility and

\section{Figure 2 Actual and projected population of the United Kingdom and constituent countries, 1971-2058}

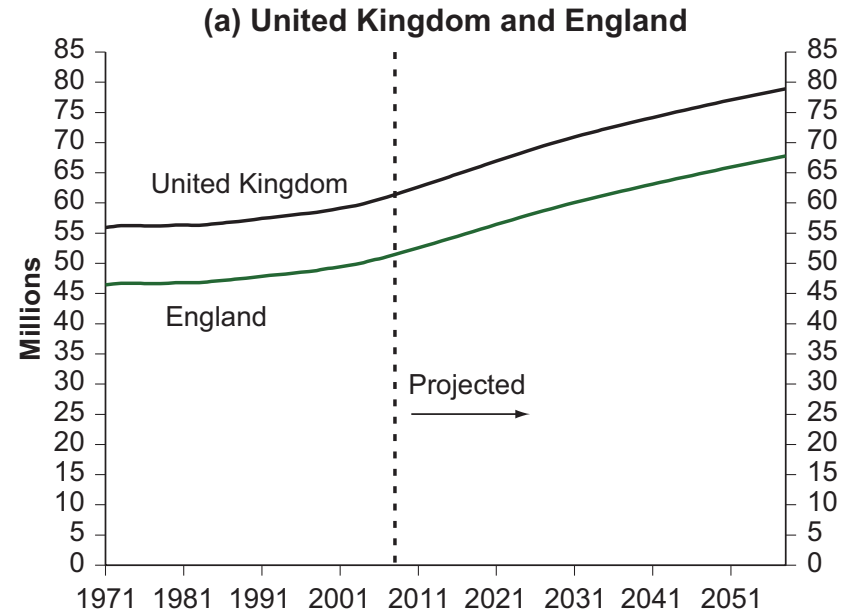

(b) Scotland, Wales and Northern Ireland

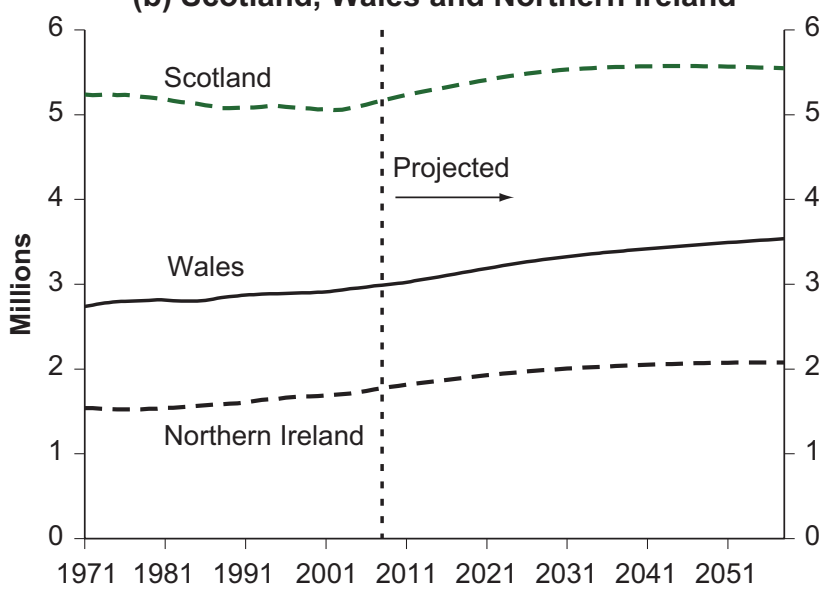


Table 3 Components of change: summary (annual averages), 2008-2033

Annual averages (thousands)

\begin{tabular}{|c|c|c|c|c|c|c|}
\hline & 2008-2011 & 2011-2016 & 2016-2021 & 2021-2026 & 2026-2031 & 2031-2033 \\
\hline \multicolumn{7}{|l|}{ United Kingdom } \\
\hline Population at start & 61,393 & 62,649 & 64,773 & 66,958 & 69,051 & 70,933 \\
\hline Births & 781 & 782 & 801 & 801 & 794 & 794 \\
\hline Deaths & 561 & 544 & 544 & 562 & 598 & 629 \\
\hline Natural change & 221 & 238 & 257 & 239 & 196 & 165 \\
\hline Net migration & 198 & 186 & 180 & 180 & 180 & 180 \\
\hline Total change & 419 & 425 & 437 & 419 & 376 & 345 \\
\hline Population at end & 62,649 & 64,773 & 66,958 & 69,051 & 70,933 & 71,623 \\
\hline \multicolumn{7}{|l|}{ England } \\
\hline Population at start & 51,460 & 52,577 & 54,472 & 56,433 & 58,334 & 60,071 \\
\hline Births & 663 & 664 & 683 & 686 & 682 & 684 \\
\hline Deaths & 462 & 448 & 447 & 463 & 492 & 519 \\
\hline Natural change & 201 & 217 & 235 & 223 & 190 & 165 \\
\hline Net migration & 172 & 162 & 157 & 157 & 157 & 157 \\
\hline Total change & 373 & 379 & 392 & 380 & 347 & 322 \\
\hline Population at end & 52,577 & 54,472 & 56,433 & 58,334 & 60,071 & 60,715 \\
\hline \multicolumn{7}{|l|}{ Wales } \\
\hline Population at start & 2,990 & 3,024 & 3,104 & 3,187 & 3,263 & 3,326 \\
\hline Births & 35 & 35 & 36 & 35 & 34 & 34 \\
\hline Deaths & 31 & 30 & 30 & 31 & 32 & 34 \\
\hline Natural change & 4 & 5 & 6 & 5 & 2 & 0 \\
\hline Net migration & 7 & 11 & 11 & 11 & 11 & 11 \\
\hline Total change & 11 & 16 & 17 & 15 & 13 & 11 \\
\hline Population at end & 3,024 & 3,104 & 3,187 & 3,263 & 3,326 & 3,347 \\
\hline \multicolumn{7}{|l|}{ Scotland } \\
\hline Population at start & 5,169 & 5,233 & 5,324 & 5,411 & 5,483 & 5,532 \\
\hline Births & 59 & 58 & 58 & 56 & 55 & 54 \\
\hline Deaths & 54 & 52 & 52 & 54 & 57 & 59 \\
\hline Natural change & 5 & 5 & 5 & 2 & -2 & -6 \\
\hline Net migration & 17 & 13 & 12 & 12 & 12 & 12 \\
\hline Total change & 21 & 18 & 17 & 14 & 10 & 6 \\
\hline Population at end & 5,233 & 5,324 & 5,411 & 5,483 & 5,532 & 5,544 \\
\hline \multicolumn{7}{|l|}{ Northern Ireland } \\
\hline Population at start & 1,775 & 1,815 & 1,874 & 1,927 & 1,971 & 2,005 \\
\hline Births & 25 & 25 & 25 & 23 & 23 & 22 \\
\hline Deaths & 14 & 14 & 14 & 15 & 16 & 17 \\
\hline Natural change & 11 & 11 & 10 & 8 & 6 & 5 \\
\hline Net migration & 2 & 1 & 1 & 1 & 1 & 1 \\
\hline Total change & 13 & 12 & 11 & 9 & 7 & 5 \\
\hline Population at end & 1,815 & 1,874 & 1,927 & 1,971 & 2,005 & 2,016 \\
\hline
\end{tabular}


life expectancy levels are assumed to remain lower than in the rest of the UK, is seven per cent . Consequently, Scotland's population is projected to increase until the mid 2040s and then start to fall.

Of the expected 10.2 million increase in the UK population between 2008 and 2033, some 5.6 million (55 per cent ) is projected natural increase (more births than deaths) while the remaining 4.6 million (45 per cent ) is the assumed total number of net migrants. However, the projected numbers of future births and deaths are themselves partly dependent on the assumed level of net migration. The overall effect of net migration on future population growth is considered in Box three.

\section{Box three Migration and population growth}

The population of the UK is projected to rise both because of positive natural change (that is, more births than deaths) and because of positive net migration. However, the components of population change are not independent of each other. In particular, the projected numbers of future births and deaths are themselves partly dependent on the assumed level of net migration.

An understanding of the overall effect of migration on population growth can be obtained by comparing the results of the principal projection with those of the zero net migration variant projection. The zero net migration variant assumes that net migration will be zero at all ages in future, but makes the same assumptions about fertility and mortality as the principal projection. In the analysis below, the effect of net migration on population growth in the period to 2033 is considered.

Clearly if annual net inward migration to the UK was to average 180,000 a year (the long-term assumption in the principal projection), this would lead to a total net inflow of 4.5 million migrants in the period between 2008 (the base year of the projections) and 2033. In fact, the projected total number of net migrants during this period in the principal projection is slightly higher (4.6 million) due to the higher migration assumptions in the first few years of the projection.

The assumed fertility and mortality rates are the same in the principal projection and the zero net migration variant projection. However, because migration is concentrated at young adult ages, the assumed number of migrants affect the number of women of childbearing age and hence the future number of births.

There is no comparable effect on deaths, at least in the period to 2033. At ages over 45 , assumed net migration flows are close to zero in the principal projection, and indeed, small net migration outflows are assumed at some older ages. So the effect of the assumed level of net migration on the number of deaths over the period to 2033 is very small.

Table A below shows the projected components of population change in the period to 2033 in the principal projection and the zero net migration variant projection. Table $\mathbf{B}$ shows how the projected population growth in the principal projection is broken down between the assumed level of net migration and projected natural change.

The population of the UK is projected to grow by 10.2 million between 2008 and 2033. Some 4.6 million of this increase is directly due to the assumed number of net migrants; natural 
change accounts for a further 5.6 million (the difference between 19.8 million births and 14.2 million deaths). Some 3.2 million of this natural increase would occur in the absence of migration. The remaining 2.4 million is, therefore, the net effect of the assumed annual level of net migration on natural change (almost entirely the effect on births).

\section{Table A Projected population change, United Kingdom, 2008-33}

Thousands

\begin{tabular}{lrr}
\hline & $\begin{array}{c}\text { Principal } \\
\text { projection }\end{array}$ & $\begin{array}{r}\text { Zero net } \\
\text { migration variant }\end{array}$ \\
\hline Population at mid-2008 & 61,393 & 61,393 \\
Population change (2008-33) & & \\
Births & 19,818 & 17,475 \\
Deaths & 14,175 & 14,208 \\
Natural change & 5,643 & 3,266 \\
Net migration & 4,586 & 0 \\
Total change & 10,229 & 3,266 \\
Population at mid-2033 & 71,623 & 64,659 \\
\hline
\end{tabular}

\section{Table B Projected population growth by component, United Kingdom, 2008-33}

Thousands

Total population increase between 2008 and 2033

10,229

Resulting from:

Assumed net migration

4,586

Natural change assuming zero net migration

3,266

Additional natural change from assumed level of net migration

2,377

Some 45 per cent of population growth in the principal projection is therefore directly attributable to the assumed number of net migrants. The remaining 55 per cent is attributable to projected natural increase (of which 32 per cent would occur in the absence of net migration and 23 per cent arises from the effect of net migration on natural change). In total, therefore, some 68 per cent of population growth in the period to 2033 is attributable, directly or indirectly, to future net migration.

It should be emphasised that these calculations are based on comparing alternative projections which make the same assumptions about future fertility and mortality rates irrespective of the assumed level of net migration. In practice, the fertility and mortality rates of migrants are likely to differ, to some extent, from those for the existing population. 
By comparing some of the special case scenario variants with the principal projection, it is possible to attempt a more detailed decomposition of future population change, distinguishing the separate effects of the fertility, mortality and migration assumptions and also the effect of 'population momentum' arising from the current age structure of the population. This is considered in Box four.

\section{Box four Components of population growth}

By comparing some of the special case scenario variants with the principal projection, it is possible to provide a more detailed decomposition of projected future population change, distinguishing the separate effects of the fertility, mortality and migration assumptions and also the effect of 'population momentum' arising from the current age structure of the population.

The following four projections are used for this analysis:

\begin{tabular}{llll}
\hline Projection & $\begin{array}{l}\text { Fertility } \\
\text { assumption }\end{array}$ & $\begin{array}{l}\text { Life expectancy } \\
\text { assumption }\end{array}$ & $\begin{array}{l}\text { Net migration } \\
\text { assumption }\end{array}$ \\
\hline Stationary variant & Replacement & No Improvement & Zero \\
Zero net migration \& constant mortality variant & Principal & No Improvement & Zero \\
Zero net migration variant & Principal & Principal & Zero \\
Principal projection & Principal & Principal & Principal \\
\hline
\end{tabular}

The stationary variant assumes 'replacement level' fertility. This is the level of fertility required for the population to replace itself in size in the long-term given constant mortality rates and in the absence of migration. ${ }^{11}$ Replacement level is now around 2.075 in the UK, that is, women would need to have, on average, 2.075 children each to ensure the long-term 'natural' replacement of the population. Under these conditions, the stationary variant will eventually produce a population with an unchanging size and age structure, but this situation may take several decades to occur. 'Population momentum' is the phenomenon by which a population continues to rise or fall in the interim and is a consequence of the initial age structure of the population.

By changing the assumptions one at a time from those used for the stationary variant to those used in the principal projection, the separate effects of the fertility, mortality and migration assumptions, and also population momentum, can be distinguished. ${ }^{12}$ This is done in Figure A and Table $\mathbf{A}$ below. As the long-term fertility assumption remains well below replacement level, fertility is still acting as a downward influence on total population size.

\section{Table A Projected population growth by component, United Kingdom} Millions

\begin{tabular}{lrrrr}
\hline & $\mathbf{2 0 1 8}$ & $\mathbf{2 0 3 3}$ & $\mathbf{2 0 5 8}$ & $\mathbf{2 0 8 3}$ \\
\hline Total population growth compared with 2008 & 4.3 & 10.2 & 17.5 & 24.3 \\
Due to: & & & & \\
$\quad$ population momentum from current age structure & 2.1 & 2.7 & 1.0 & 0.4 \\
assumed below replacement fertility & -0.8 & -2.1 & -5.8 & -10.7 \\
assumed mortality improvement & 0.7 & 2.7 & 5.7 & 7.1 \\
assumed inward net migration & 2.3 & 7.0 & 16.6 & 27.5 \\
\hline
\end{tabular}




\section{Figure A Projected UK total population, 2008 to 2083}

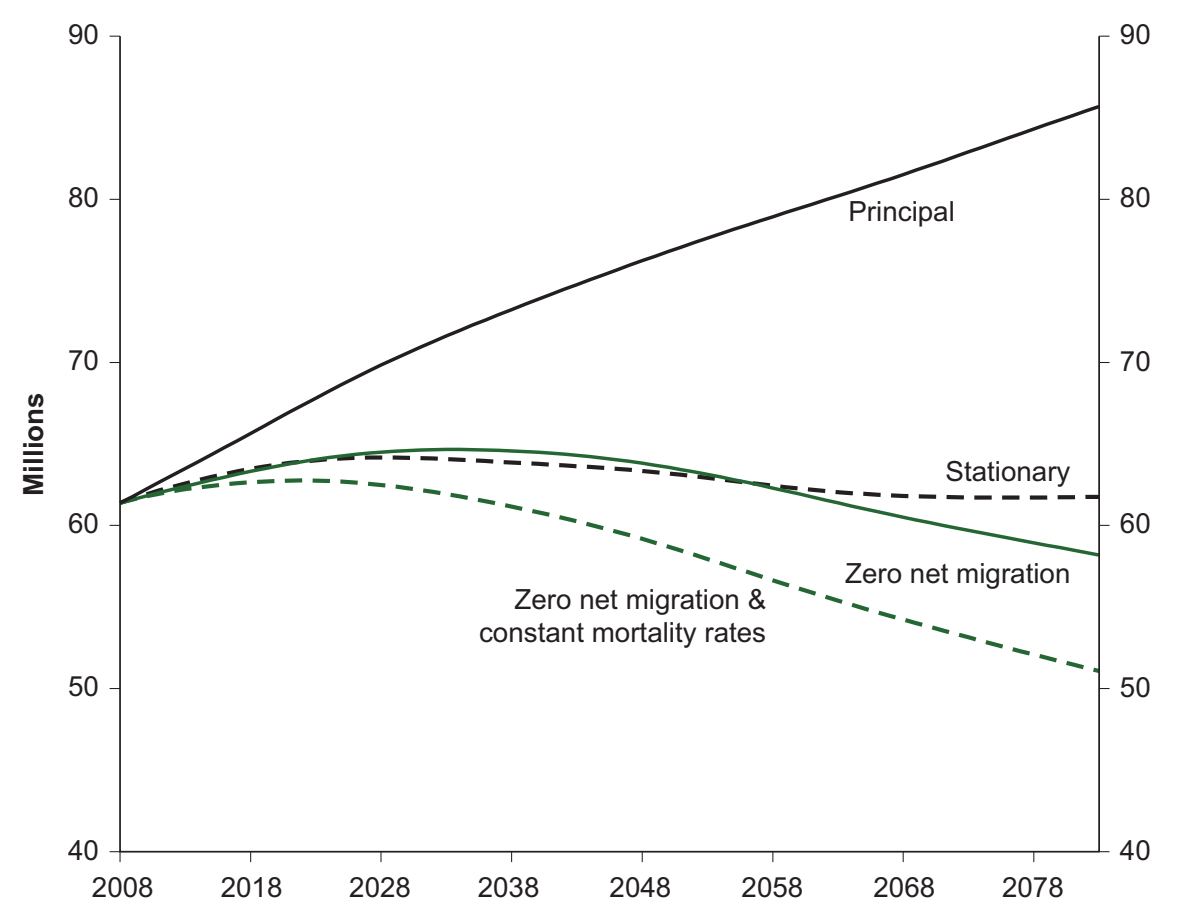

Figure A shows that under the stationary variant conditions, the UK population would eventually stabilise at around 62 million. However, this would not happen immediately. Indeed, in the stationary variant, the UK population is projected to continue growing until the late 2020 s, and would be 2.7 million higher in 2033 than in 2008 . The fact that the population increases in the medium-term with replacement fertility, even with constant mortality rates and no migration, is because of the present age structure of the UK population. Births would continue to exceed deaths under these conditions over the next twenty years.

The 'zero migration \& constant mortality' variant uses the principal fertility assumption of a longterm average of 1.84 children per woman but is otherwise the same as the stationary variant. Comparison of these two variants therefore shows the effect of assuming that long-term fertility will be about ten per cent below replacement level. Compared with the stationary variant, the projected population of the UK at 2033 is 2.1 million lower because of the assumption of below replacement level fertility.

Similarly, the 'zero migration' variant differs from the 'zero migration \& constant mortality' variant only in the mortality assumption used. Comparison of these two variants therefore shows the effect of assuming that mortality rates will not remain constant but will continue to improve as envisaged in the principal projection. The effect of the mortality improvement assumed in the principal projection is to add about 2.7 million to the population at 2033.

Finally, the impact of the assumed level of net migration in the principal projection can be assessed by comparing the principal projection with the zero migration variant. This shows that the effect of the principal migration assumption is to add a further 7.0 million to the population at 2033. This represents 68 per cent of the total projected population growth between 2008 and 2033. The impact of migration on population growth is considered in more detail in Box three. 


\section{Figure 3 Actual and projected births and deaths, United Kingdom,} 1971-2058

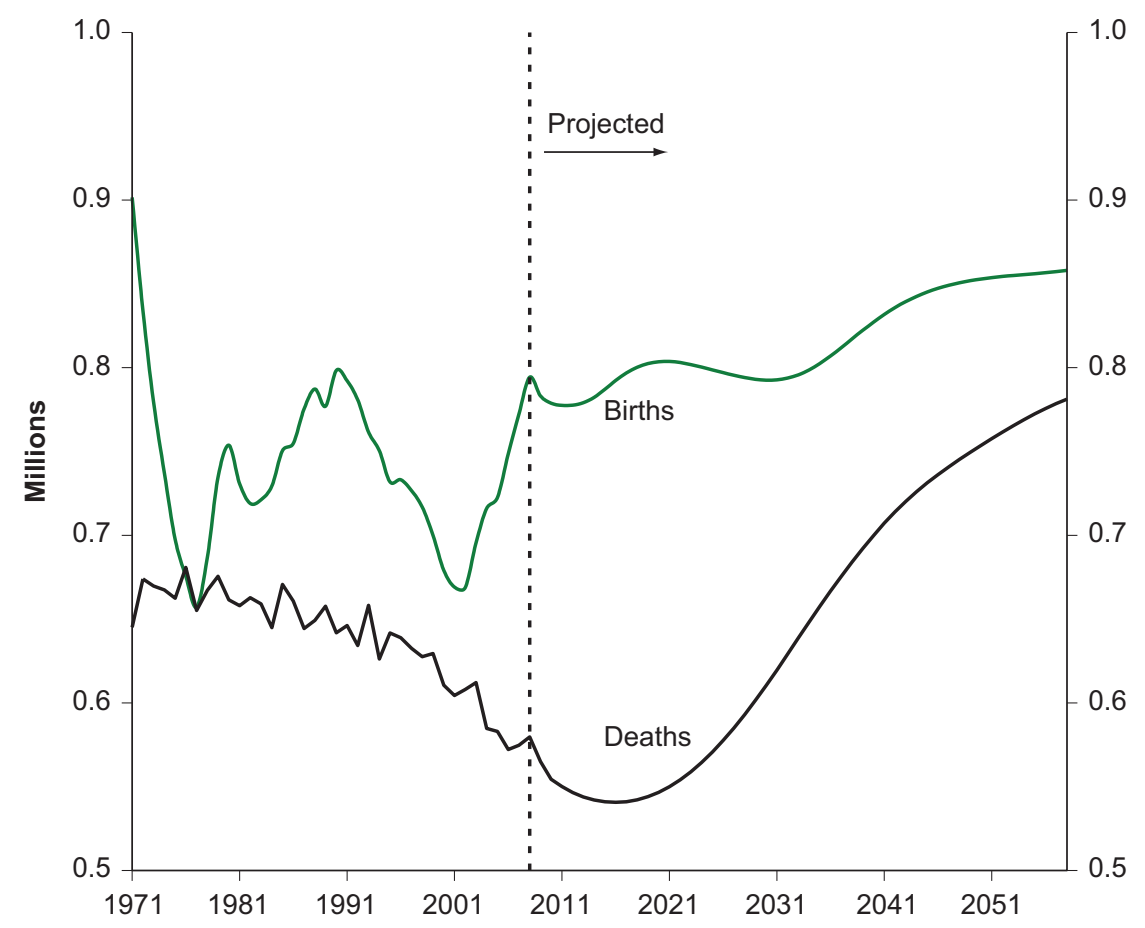

\section{Births and deaths}

Projected numbers of births and deaths are shown in Figure 3. With the single exception of 1976, the UK gained population through natural increase (births less deaths) throughout the 20th century. In the 2008-based projections natural increase remains positive throughout the projection period. Of course, these projections are subject to considerable uncertainty. In particular, the projected trend in births depends on the assumed future level of fertility (including that for women not yet born) and has much greater uncertainty attached to it than the projected trend in deaths which is largely determined by the age structure of the population alive today.

\section{Age distribution}

Table 4 and Figure 4 summarise the projected age structure of the population. The age structure will become gradually older with the median age of the population projected to rise from 39.3 years in 2008 to 42.2 years by 2033. Longer-term projections show continued ageing with the median age exceeding 43 years by 2058 .

The number of children aged under 16 is projected to increase by 6.2 per cent from 11.5 million in 2008 to 12.2 million in 2018 and then to increase further to 12.8 million by 2033. After levelling off for a few years, the increase is expected to resume around 2040 and reach 13.6 million by 2058.

Allowing for the forthcoming changes to state pension age ${ }^{13}$ (from 60 to 65 for women between 2010 and 2020, and then from 65 to 66 for both sexes between 2024 and 2026), the working age population is projected to rise by 14 per cent from 38.1 million in 2008 to 43.3 million in 2033. The working age population will become much older as the baby boom generations of the mid 1960s age. In 2008, there were 1.5 million (8.3 per cent) more working age adults aged below 40 than 
Table 4 Projected population by age, United Kingdom, 2008-2033

\begin{tabular}{lrrrrrr}
\hline Age Group & $\mathbf{2 0 0 8}$ & $\mathbf{2 0 1 3}$ & $\mathbf{2 0 1 8}$ & $\mathbf{2 0 2 3}$ & $\mathbf{2 0 2 8}$ & $\mathbf{2 0 3 3}$ \\
\hline All ages & 61,393 & 63,498 & 65,645 & 67,816 & 69,832 & $\mathbf{7 1 , 6 2 3}$ \\
0-14 & 10,753 & 11,001 & 11,550 & 11,851 & 11,942 & 11,963 \\
$15-29$ & 12,293 & 12,700 & 12,269 & 12,057 & 12,301 & 12,850 \\
30-44 & 12,978 & 12,498 & 12,826 & 13,821 & 14,181 & 13,757 \\
45-59 & 11,795 & 12,660 & 13,170 & 12,638 & 12,185 & 12,533 \\
60-74 & 8,798 & 9,444 & 10,036 & 10,498 & 11,366 & 11,871 \\
75 \& over & 4,776 & 5,194 & 5,794 & 6,951 & 7,858 & 8,650 \\
Median age (years) & 39.3 & 40.0 & 40.0 & 40.5 & 41.3 & 42.2 \\
Under 16 (A) & 11,517 & 11,718 & 12,236 & 12,645 & 12,723 & 12,764 \\
Working age* (B) & 38,083 & 39,419 & 40,848 & 41,763 & 43,062 & 43,270 \\
Pensionable age* (C) & 11,794 & 12,362 & 12,561 & 13,408 & 14,047 & 15,589 \\
Support ratios & & & & & 3.304 \\
Young (B/A) & 3.31 & 3.36 & 3.34 & 3.30 & 3.38 & 3.39 \\
Old (B/C) & 3.23 & 3.19 & 3.25 & 3.11 & 3.07 & 2.78 \\
Total (B/(A + C)) & 1.63 & 1.64 & 1.65 & 1.60 & 1.61 & 1.53 \\
\hline
\end{tabular}

* Working age and pensionable age populations based on the state pension age for given year. Between 2010 and 2020, state pension age will change from 65 for men and 60 years for women, to 65 years for both sexes. Between 2024 and 2026, state pension age will increase from 65 to 66 for both sexes.

Figure 4 Actual and projected age distribution, United Kingdom, 1981-2058

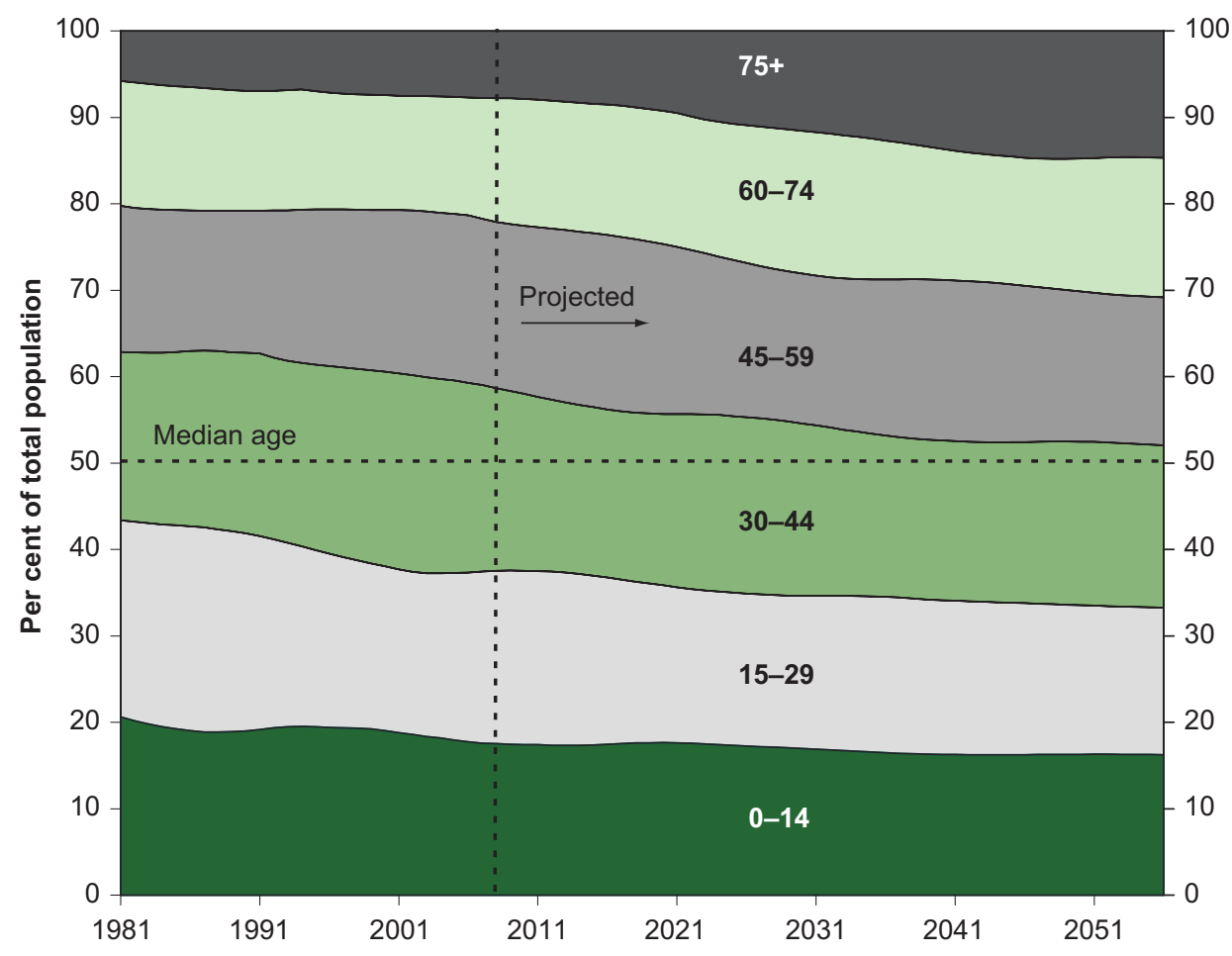


were aged 40 and above. However, by 2033 there are projected to be 1.4 million (6.5 per cent ) more working age people above 40 than below 40 .

Again, allowing for the forthcoming changes to state pension age, the number of people of state pensionable age is projected to increase by 32 per cent from 11.8 million in 2008 to 15.6 million in 2033. In the longer-term, further increases in state pension age to reach 68 by 2046 will curb the increase in the population of pensionable age, although a faster increase will again return after the changes in state pension age are complete.

As the population ages, the numbers in the oldest age bands will increase the fastest. In 2008 , there were 4.8 million people in the UK aged 75 and over. The number is projected to increase to 5.8 million by 2018 and to 8.7 million by 2033 , a rise of 81 per cent over 25 years. Over the same period, the number of people aged 85 and over is projected to more than double (from 1.3 million in 2008 to 3.3 million in 2033), whilst the number of centenarians is projected to increase more than sevenfold (from 11,000 in 2008 to 80,000 in 2033).

\section{Support ratios}

These changes in age structure will, in time, have a marked effect on the future proportion of pensioners in the population. Figure $\mathbf{5}$ shows the projected old age support ratio, that is the ratio of persons of working age to those of state pensionable age. The ratios are based on the state pension age for the given year and take account of the planned future changes to that age. It should be emphasised, however, that demographically defined support ratios such as these, whatever age boundaries are used, take no account of workforce participation rates and therefore do not represent real levels of economic dependence. In reality, full-time education ends, and retirement starts, at a range of ages.

\section{Figure 5 Actual and projected old age support ratio, United Kingdom, 1981-2058}

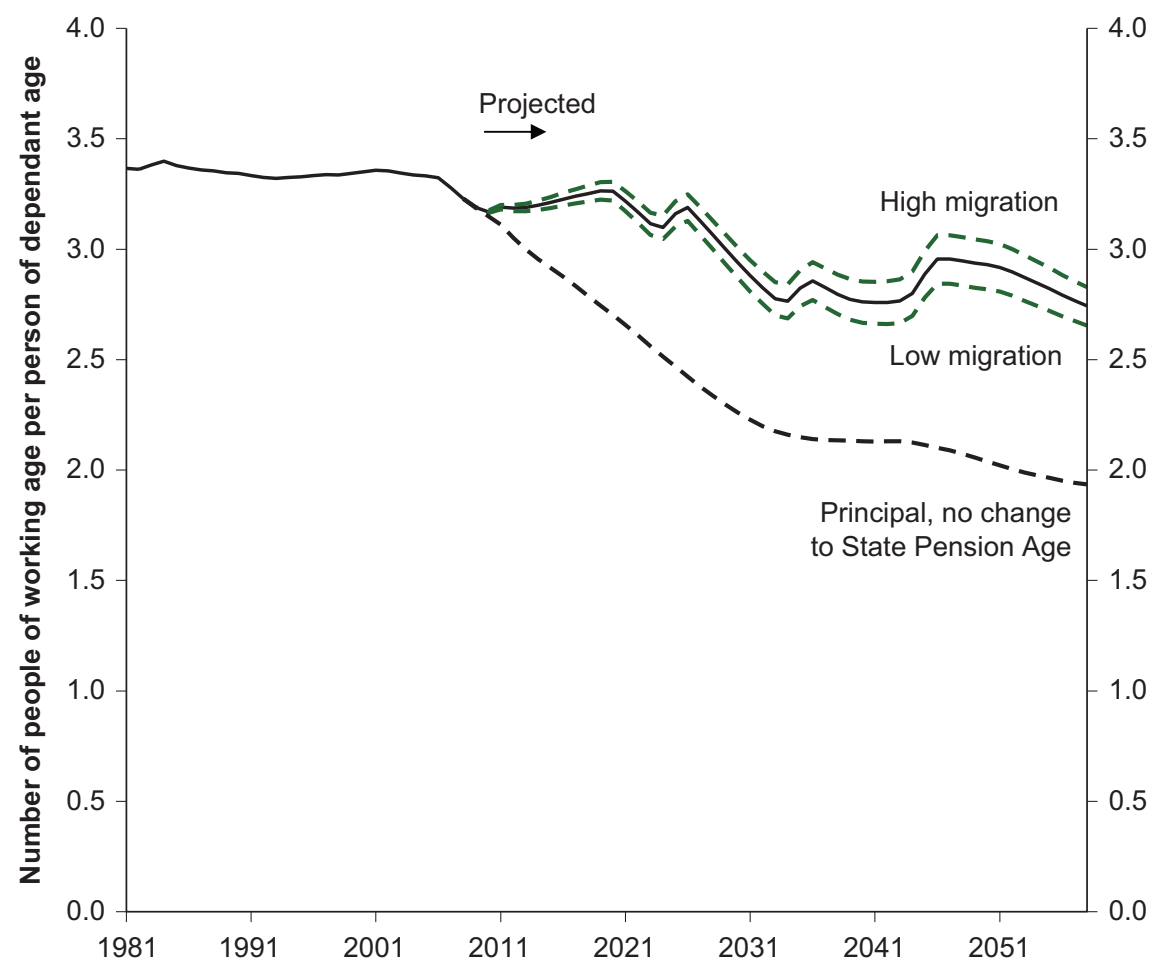


In 2008, there were 3.23 persons of working age for every person of state pensionable age. Allowing for the forthcoming changes in state pension ages, this old age support ratio is projected to fall to 2.78 by 2033 .

Although the old age support ratio are projected to fall in the future, Figure 5 shows how the future changes to state pension age help to moderate this decline. Allowing for all the changes between 2010 and 2046, the old age support ratio is projected to decline to 2.74 by 2058 . However, were state pension ages to have remained as they are today (65 years for men and 60 years for women) it is projected that the ratio would fall considerably further - to 1.94 by 2058 .

Comparison of the principal projection with the high and low migration variants show how future net migration will impact upon the old age support ratio. If annual net migration to the UK were to be 60,000 lower than assumed for the principal projection (that is $+120,000$, rather than $+180,000$ ), the old age support ratio would fall to 2.70 by 2033. In contrast, if annual net migration to the UK were to be 60,000 higher (that is, $+240,000$ ), the old age support ratio would be 2.85 by 2033 .

\section{Comparison with 2006-based projections}

The projected total population of each country is compared with the 2006-based projections in Table 5 and the difference between the two projections is broken down into changes in the base population and changes in the projected numbers of births, deaths and net migrants. Decreases in the projected numbers of deaths (as compared with the previous projections) are shown as positive numbers in the table as they contribute to increases in the size of the population.

The projected population of the UK at 2033 is 153,000 (0.2 per cent ) lower than in the 2006-based projections. This is due to a combination of slightly fewer births, fewer migrants and fewer deaths. The assumed annual number of migrants is lower than in the previous projections, and this in turn has led to slightly fewer births being projected despite the fertility assumption for the UK as a whole remaining unchanged. The projected number of deaths is less than for the 2006-based projections, as slightly higher life expectancies have been assumed for the current projections.

The projected populations of Wales, Northern Ireland, and particularly Scotland, in 2033 are higher than in the 2006-based projections, due to higher net migration assumptions being made for

\section{Table 5 Change in projected population at 2033 compared with the 2006-based projections}

\begin{tabular}{|c|c|c|c|c|c|c|c|}
\hline \multirow[t]{2}{*}{ Country } & \multirow{2}{*}{$\begin{array}{l}\text { 2008-based } \\
\text { projections }\end{array}$} & \multirow{2}{*}{\multicolumn{2}{|c|}{$\begin{array}{l}\text { 2006-based Total change } \\
\text { projections }\end{array}$}} & \multicolumn{4}{|c|}{ Change due to } \\
\hline & & & & $\begin{array}{r}\text { base } \\
\text { population* }\end{array}$ & $\begin{array}{r}\text { projected } \\
\text { births }\end{array}$ & $\begin{array}{r}\text { projected } \\
\text { deaths }^{* *}\end{array}$ & $\begin{array}{r}\text { projected } \\
\text { migrants }\end{array}$ \\
\hline England & 60,715 & 61,085 & -369 & -28 & -154 & 192 & -380 \\
\hline Wales & 3,347 & 3,311 & 37 & -3 & 13 & 14 & 13 \\
\hline Scotland & 5,544 & 5,371 & 173 & 11 & 63 & 5 & 94 \\
\hline Northern Ireland & 2,016 & 2,010 & 6 & 1 & 2 & 1 & 1 \\
\hline United Kingdom & 71,623 & 71,776 & -153 & -18 & -76 & 212 & -271 \\
\hline
\end{tabular}

* Difference between the base population at mid-2008 and the 2006-based projection of the population at mid-2008.

** Decreases in the projected number of deaths (compared with the previous projections) are shown as positive numbers as they contribute to an increase in the size of the population. 
these countries in the latest projections, and also a slightly higher fertility assumption for Scotland. In contrast, the projected population of England in 2033 is over 350,000 lower than for the 2006-based projection, due to the reduction in the net migration assumption for England.

\section{Sensitivity}

The one certainty of making population projections is that, due to the inherent unpredictability of demographic behaviour, they will not turn out to be an accurate forecast of future demographic events or population structure. One way of giving users an indication of uncertainty is by considering the performance of past projections. An analysis of the accuracy of UK national population projections made over the last fifty years was published in Population Trends 128 in summer $2007 .{ }^{14}$ A second article looking at the accuracy of population projections made by 14 European countries, including the UK, was published in Population Trends 129 in autumn $2007 .{ }^{15}$

Another way of illustrating uncertainty is by preparing variant projections based on alternative assumptions of future fertility, mortality and migration. Since the 2000-based projections, an extensive range of variant projections, at both UK and individual country level, has been produced for each 'full' set of projections. Full details of the latest 2008-based variant projections are available on the ONS website. ${ }^{16}$

Compared with the principal projection assumptions, the high and low fertility variants assume long term family sizes of \pm 0.2 children per woman. In the high and low mortality variants, projected life expectancy at birth at 2033 differs by \pm 1.9 years for males and \pm 1.2 years for females from the principal assumption. Finally, in the high and low migration variants, the long-term annual net migration inflows are assumed to be 60,000 persons above and below the principal assumption. These variant assumptions are intended as plausible alternative scenarios and not as upper or lower limits for what might occur in the future. Figure 6 and Figure 7 show the total population of the UK and the percentage of the population aged over 65 under these alternative assumptions.

It is clear from Figure 6 that there is considerable uncertainty regarding the future size of the population. Under the alternative, but still plausible, fertility and migration assumptions, the population at 2033 differs from the principal projection by around \pm 2 million. The uncertainty widens with time and by 2083 the population would be over 10 million higher or lower than in for the principal projection under the high and low fertility assumptions. Figure 6 shows that the population continues to grow under all of the main variant projections. However, because the variant assumptions are plausible alternatives rather than upper or lower limits, continued population growth is not a certainty. Indeed, if a combination of the low fertility, life expectancy and migration assumptions is considered (the 'low population' variant projection), it is projected that the UK population would peak at 67.6 million in 2042.

Figure 7 demonstrates that significant population ageing will occur under any plausible set of future assumptions. In 2008, some 16 per cent of the UK population were aged 65 and over. The proportion aged over 65 is projected to increase to between 21.3 per cent and 24.6 per cent by 2033 . In the principal projection, the proportion aged 65 and over would continue increasing, reaching over 27 per cent by 2083. In the high life expectancy variant, this would be over 30 per cent, and if a combination of low fertility, high life expectancy and low migration is considered (the old age structure variant), over a third of the UK population would be aged 65 and over in 75 years' time. 
Figure 6 Population of the United Kingdom according to principal and variant 2008-based projections, 1981-2083

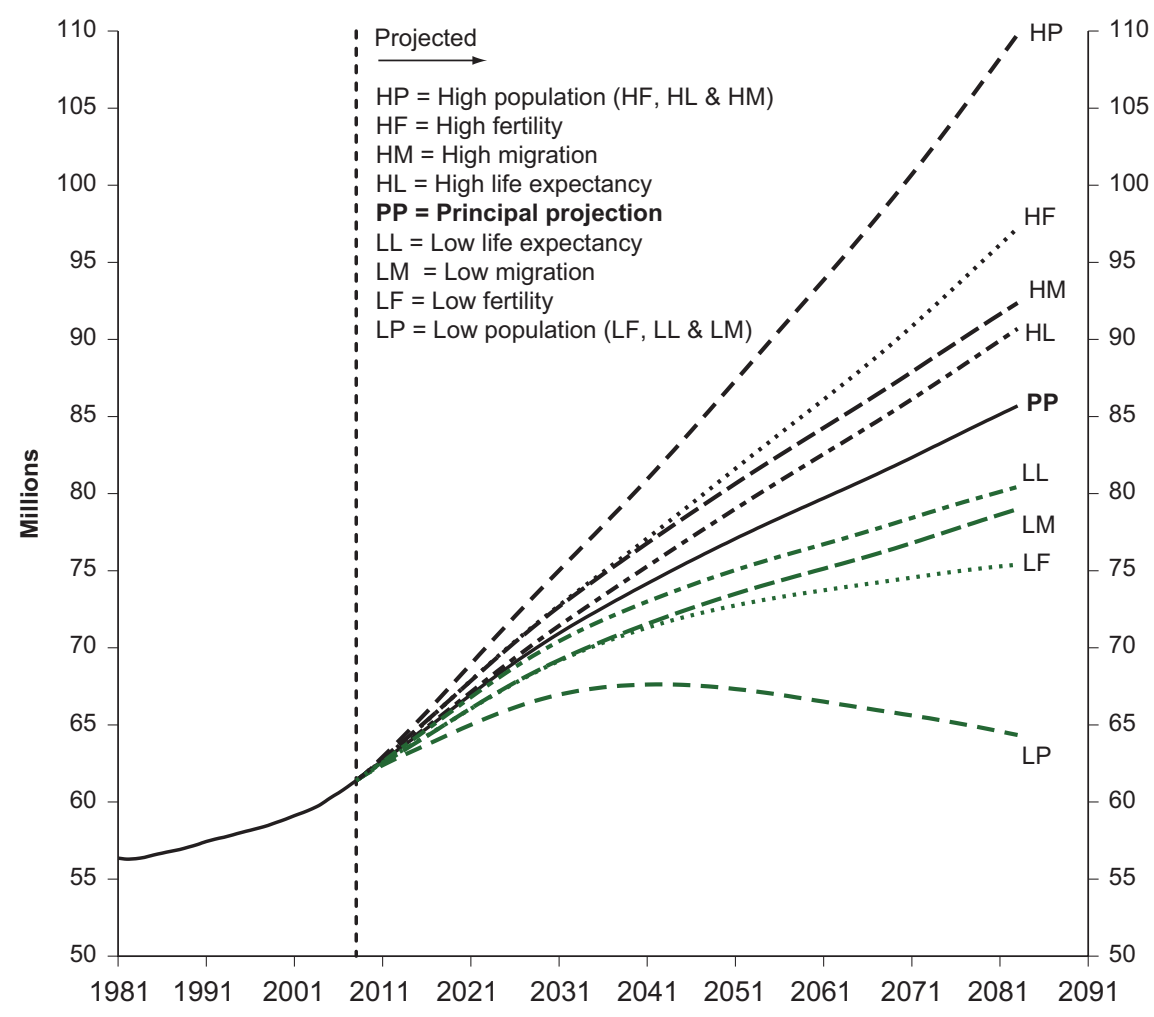

Figure 7 Proportion of the population aged 65 and over according to principal and variant 2008-based projections, United Kingdom, 1981-2083

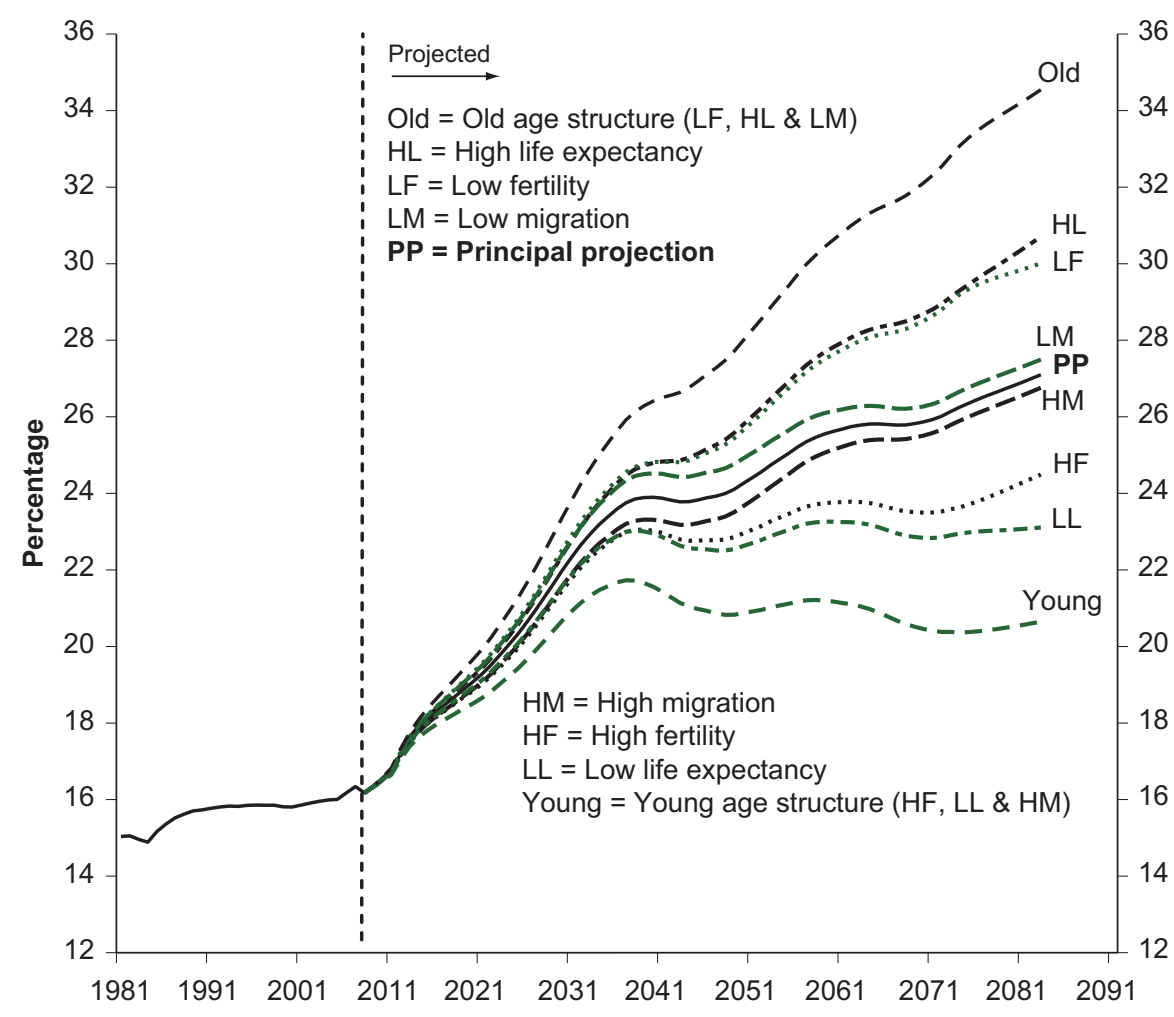


The pattern and inevitability of population ageing is a consequence of the current age structure of the population. This, in turn, is a result of changes in the past numbers of births. Thus over the next few years, the number of older people will start to rise rapidly as the relatively large cohorts born after the Second World War and during the 1960s baby boom enter the 65 and over age group and replace the much smaller cohorts born before 1945. A new dynamic population pyramid tool is now available on the ONS website ${ }^{17}$ which allows projected changes to the age structure of the UK population to be compared between the 2008-based principal and variant projections.

\section{Key findings}

Based on the assumptions underlying the principal projections:

- The UK population is projected to increase from an estimated 61.4 million in 2008 to reach 71.6 million by 2033

- Of the 10.5 million increase between 2008 and 2033 in the principal projection, some 5.6 million (55 per cent ) is projected natural increase (more births than deaths) while the remaining 4.6 million ( 45 per cent) is the assumed total number of net migrants. However, projected births and deaths are partly dependent on the assumed level of net migration. Allowing for the additional impact of migration on natural change, it is estimated that some 68 per cent of projected population growth in the period to 2033 is attributable, directly or indirectly, to net migration

- The UK population will gradually become older, with the median age expected to rise from 39.3 years in 2008 to 42.2 years in 2033

- In 2008 there were 3.23 persons of working age for every person of state pensionable age. By 2033 , this old age support ratio is projected to decline to 2.78 , despite the forthcoming changes in state pension age

- Due to differences in demographic patterns, projected trends differ for the four countries of the UK. The population of England is projected to increase by 18 per cent by 2033, Northern Ireland by 14 per cent and Wales by 12 per cent. The projected increase for Scotland, where fertility and life expectancy levels are assumed to remain lower than in the rest of the UK, is 7 per cent.

\section{References}

1 Full results of the 2008-based national population projections are available at: www.statistics.gov.uk/StatBase/Product.asp?vlnk=8519

2 Results for previous national population projections are available at: www.gad.gov.uk/Demography\%20Data/Population/index.aspx

3 Details of the membership of the National Population Projections Expert Advisory Panel are available at: www.statistics.gov.uk/downloads/theme_population/NPP2008/NatPopProj2008.pdf (see section 11)

4 Office for National Statistics (2010) National population projections: 2008-based. ONS Series PP2 no.27. Available at: www.statistics.gov.uk/statbase/Product.asp?vInk=4611 
5 2008-based subnational population projections for Scotland are available at: www.gro-scotland.gov.uk/statistics/publications-and-data/popproj/2008-based-pop-proj-scottishareas/index.html

6 Office for National Statistics (2009) Population Estimates Statistical Bulletin (27 August 2009). Available at: www.statistics.gov.uk/pdfdir/pop0809.pdf

7 Details of the package of improvements to population estimates are available at: www.ons.gov.uk/about-statistics/methodology-and-quality/imps/updates-reports/index.html

8 Latest 2008-based period and cohort life expectancy tables available at: www.statistics.gov.uk/STATBASE/Product.asp?vlnk=15098

9 Full details of the latest migration assumptions are provided in Chapter 8 of the 2008-based National Population Projections Reference Volume, available at: www.statistics.gov.uk/statbase/Product.asp?vlnk=4611

10 Office for National Statistics (2009) Migration Statistics 2008 Statistical Bulletin (26 November 2009). Available at: www.statistics.gov.uk/pdfdir/miga1109.pdf

11 Smallwood S and Chamberlain J. (2005) 'Replacement fertility, what has it been and what does it mean?' Population Trends 119, 16-27. Available at: www.statistics.gov.uk/statbase/Product.asp?vlnk=6303

12 In this analysis, the fertility assumption is changed first, then the mortality assumption and finally the migration assumption. Because the components interact with each other, the results would be slightly different if a different order was used. But this will not affect the broad conclusions drawn.

13 Details of the forthcoming changes to state pension age are available at: www.statistics.gov.uk/downloads/theme_population/NPP2008/NatPopProj2008.pdf (see section 6)

14 Shaw C (2007) 'Fifty years of United Kingdom national population projections: how accurate have they been?' Population Trends 128, 8-23. Available at: www.statistics.gov.uk/statbase/Product.asp?vlnk=6303

15 Keilman N (2007) 'UK national population projections in perspective: How successful compared to those in other European Countries?' Population Trends 129, 20-30. Available at: www.statistics.gov.uk/statbase/Product.asp?vlnk=6303

16 Details of the 2008-based variant projections are available at: www.statistics.gov.uk/downloads/theme_population/NPP2008/NatPopProj2008.pdf (see section 4)

17 United Kingdom interactive population pyramid: National population projections - principal and variants. Available at: www.statistics.gov.uk/nationalprojections/flash_pyramid/default.htm 